\title{
Therapeutic options of giant liver hemangioma
}

\begin{abstract}
Liver hemangiomas are commonly the most frequent benign lesion of the liver. They are generally smaller, asymptomatic and diagnosed incidentally in imaging studies. A liverhemangioma is qualified giant when it has a size larger than $5 \mathrm{~cm}$. Asymptomatic and non-complicated giant liver are managed conservatively by observation. However, lesion with incapacitating symptoms or complications is managed surgically. Surgery remains the most effective and radical therapeutic modality to treat liver hemangioma. Thus both enucleation and liver resection can be performed to remove the lesion. However recent studies demonstrated that enucleation was a safer, Quaker surgical procedure and associated with lower complication and less blood loss. Non-surgical treatment options have been described to be used alone or in combination with surgery. This mini-review provides a general view of the therapeutic options employed to treat giant liver hemangioma.
\end{abstract}

Keywords: giant liver hemangioma, observation, surgery, resection, enucleation
Volume 4 Issue I - 2018

\author{
Abdelkader Boukerrouche \\ Department of Digestive Surgery, University of Algiers, Algeria
}

Correspondence: Boukerrouche A, Department of Digestive Surgery, Hospital of Beni-Messous, University of Algiers, 16002 Algiers, Algeria, Tel +213661227298, Fax+21321931310, Email aboukerrouch@yahoo.com

Received: December 22, 2018 | Published: February 06, 2018

\section{Introduction}

Liver hemangiomas are often asymptomatic, smaller and diagnosed incidentally. A giant hemangioma is defined as a lesion with a diameter greater than $5 \mathrm{~cm}$. Giant hemangiomas can become symptomatic and may cause mechanical complications related to tumour size. ${ }^{1}$ Also, complications such as coagulation disorders, bleeding and traumatic rupture can occur during conservative management period. ${ }^{1}$ Asymptomatic and non-complicated giant hemangiomas can be safely observed with lower adverse events and the hemangioma size alone is not supported for indication of surgery even for very large lesion. ${ }^{2-4}$ Severe incapacitating symptomatology or complications occurred during observation are justifiable of surgical management. ${ }^{2-6}$ Surgery is the most effective therapeutic modality to treat liver hemangioma. ${ }^{4,6}$ A hemangioma can be removed by enucleation or liver resection however, most authors advocated enucleation procedure. In very rare and exceptional condition, Liver transplantation can be considered as a treatment option for hemangioma. ${ }^{7-10}$ Other therapeutic options as Radiofrequency ablation (RFA) and transcatheter arterial embolization (TAE) can be considered in some situations. This minireview provides a general view of the therapeutic options employed to treat giant liver hemangioma.

\section{Observational approach}

The management of giant liver hemangioma (GLH) varies from observation to a variety of non-surgical and surgical procedures. The published studies assessing observation of giant liver hemangiomas demonstrated that health status and quality of life of observed patients varied from good to excellent concluding that observation was safe in most patients. ${ }^{11}$ Conservative approach is justified even in very large hemangiomas and tumour size alone is not supported as an indication for urgery. ${ }^{12-17}$ Thus, asymptomatic and non-complicated giant liver hemangioma can be safely observed by supervision through regular imaging control with lower risk of adverse events. ${ }^{2,15-21}$

\section{Non-surgical therapies}

Non-surgical options have been described and proposed as therapeutic methods of giant liver hemangiomas including transarterial embolization (TAE) and radiofrequency ablation (RFA). A possible reduction of symptoms has been noted after TAE, however, there was no change in tumour size and recurrence was common. ${ }^{22}$ In complicated hemangioma, transarterial embolization is used before surgery to stabilize ruptured lesion. In an extremely large lesion, Preoperative TAE is widely performed to decrease blood supply and to reduce tumour size making thus definitive surgery easier and less risked. ${ }^{22-27}$ Radiofrequency ablation was successful to control symptomatic smaller lesions $\left(5-10 \mathrm{~cm}\right.$ diameter) ${ }^{28}$ However, RFA is associated with high rate of complications in lesion greater than $10 \mathrm{~cm}$ and its use is inappropriate in very large hemangioma $(>10 \mathrm{~cm}){ }^{28}$

\section{Surgical approach}

The indications of surgery for giant liver hemangioma is well defined and symptomatic or complicated lesions are the most conditions requiring surgical management.,13,18,29-31 Combined use of advanced various imaging techniques allows to establish diagnostic certainty in most cases. Nowadays uncertainty of diagnosis is become a rare criterion for surgical treatment. ${ }^{20,32}$ Furthermore surgery remains the effective therapeutic method to treat liver hemangioma. Surgery includes liver resection, enucleation and transplantation. ${ }^{29}$ A rare cases of liver transplantation performed for diffuse hepatic hemangiomatosis, lesions anatomically unresectable by conventional approaches and in patients with Kasabach-Merritt syndrome, have been reported. ${ }^{7-10}$ However there is a shortage of liver graft and the need of a long-term anti-immunologic treatment in transplanted patients. When surgery is indicated, hemangioma can be removed by both liver resection and enucleation procedures. The choice between liver resection and enucleation depends mainly on location, number and size tumor, complications, preference and technical skills of surgeon. ${ }^{33,34}$ Enucleation is more preferred in peripheral and rightsided located hemangioma. Also it is more suitable in case of multiple locations leading to preserve normal liver parenchyma. ${ }^{12,33,34}$ Liver anatomic resection is more preferred in centrally located lesion or when lesion is near or compresses large vessels with high risk of bleeding and prolonged operative time ${ }^{35-37}$ However the risk of blood loss and transfusion is more related to hemangioma size and very large lesion $(>20 \mathrm{~cm})$ is associated with high risk of operative bleeding. 
In such condition, liver anatomic resection is the more suitable procedure. ${ }^{33,34}$ Complications such as bleeding and rupture occurred during observation constitute an emergency situation, and in such condition liver resection is more preferable to avoid aggravation of a serious situation and to minimize the risk of operative complications. ${ }^{37}$ According to advances made in liver surgery, enucleation meets the requirement of precise liver surgery which is precision, minimal invasiveness, and effectiveness..$^{21}$ Results of recent meta-analyses comparing outcomes of enucleation versus those of anatomic resection for giant liver hemangioma revealed no surgery-related death in both enucleation and resection, however, enucleation was associated with significantly lower blood loss, lower operative time, and lower risk of complications. ${ }^{38,39}$ Most authors advocated enucleation because it is safer and quicker with lower overall complications and less blood loss. ${ }^{18,29,33,40-42}$ An increase in mini-invasive surgical procedures for liver benign tumors including hemangiomas has been reported in the last two decades. ${ }^{6}$ This progress is technically explained by the no need to radical margin and liver normal parenchyma is more easily manageable. ${ }^{6}$ The indications for the laparoscopic approach are the same as those of open surgery. Mini-invasive resection of anterior location hemangioma can be performed easily. However the impact of a minimal approach in reducing operative risk or complications is not clearly defined. ${ }^{43-46}$

\section{Conclusion}

In summary, as demonstrated and admitted by authors, asymptomatic or con complicated giant liver hemangiomas can be safely observed with the very lower risk of complications. When surgery is indicated, giant liver hemangiomas can be safely removed by either enucleation or liver anatomic resection. Compared to resection, enucleation is associated with lower morbidity and less blood loss. Hence, this surgical procedure is advocated by most surgeons to treat liver hemangioma. Transarterial embolization (TAE) and radiofrequency ablation are to be considered before surgery in an extremely large lesion to reduce the risk of bleeding and complications.

\section{Acknowledgements}

None.

\section{Conflict of interest}

The authors have no conflict of interest to report.

\section{References}

1. Weimann A, Ringe B, Klempnauer J, et al. Benign liver tumors: differential diagnosis and indications for surgery. World J Surg. 1997;21(9):983-990.

2. Yoon SS, Charny CK, Fong Y, et al. Diagnosis, management, and outcomes of 115 patients with hepatic hemangioma. J Am Coll Surg. 2003;197(3):392-402.

3. Erdogan D, Busch OR, van Delden OM, et al. Management of liver hemangiomas according to size and symptoms. J Gastroenterol Hepatol. 2007;22(11):1953-1958.

4. Hoekstra LT, Bieze M, Erdogan D, et al. Management of giant liver hemangiomas: an update. Expert Rev Gastroenterol Hepatol. 2013;7(3):263-268.

5. Belghiti J, Cauchy F, Paradis V, et al. Diagnosis and management of solid benign liver lesions. Nat Rev Gastroenterol Hepatol. 2014;11(12):737-749.
6. Toro A, Mahfouz AE, Ardiri A, et al. What is changing in indications and treatment of hepatic hemangiomas. A review. Ann Hepatol. 2014;13(4):327-339.

7. Meguro M, Soejima Y, TaketomiA, et al. Living donor liver transplantation in a patient with giant hepatic hemangioma complicated by KasabachMerritt syndrome: report of a case. Surg Today. 2008;38(5):463-468.

8. Vagefi PA, Klein I, Gelb B, et al. Emergent orthotopic liver transplantation for haemorrhage from a giant cavernous hepatic hemangioma: case report and review. J Gastrointest Surg. 2011;15(1):209-214.

9. Ferraz AAB, Sette MJA, Maia M, et al. Liver transplant for the treatment of giant hepatic hemangioma. Liver Transpl. 2004;10(11):1436-1437.

10. Browers MAM, Peeters PMJG, de Jong KP, et al. Surgical treatment of giant haemangioma of the liver. Br J Surg. 1997;84(3):314-316.

11. Farges O, Daradkeh S, Bismuth H. Cavernous hemangiomas of the liver: are there any indications for resection? World J Surg. 1995;19(1):19-24.

12. Giuliante F, Ardito F, Vellone M, et al. Reappraisal of surgical indications and approach for liver hemangioma: single-centre experience on 74 patients. Am J Surg. 2011;201(6):741-748.

13. Yedibela S, Alibek S, Müller V, et al. Management of hemangioma of the liver: surgical therapy or observation? World J Surg. 2013;37(6):1303-1312.

14. Yamagata M, Kanematsu $T$, Matsumata $T$, et al. Management of haemangioma of the liver: comparison of results between surgery and observation. Br J Surg. 1991;78(10):1223-1225.

15. Schnelldorfer T, Ware AL, Smoot R, et al. Management of giant hemangioma of the liver: resection versus observation. J Am Coll Surg. 2010;211(6):724-730.

16. Pietrabissa A, Giulianotti P, Campatelli A, et al. Management and followup of 78 giant haemangiomas of the liver. Br J Surg. 1996;83(7):915-918.

17. Herman P, Costa ML, Machado MA, et al. Management of hepatic hemangiomas: a 14-year experience. J Gastrointest Surg. 2005;9(6):853-859.

18. Terkivatan T, Vrijland WW, Den Hoed PT, et al. Size of lesion is not a criterion for resection during management of giant liver haemangioma. Br J Surg. 2002;89(10):1240-1244.

19. Charny CK, Jarnagin WR, Schwartz LH, et al. Management of 155 patients with benign livertumours. Br J Surg. 2001;88(6):808-813.

20. Mezhir JJ, Fourman LT, Do RK, et al. Changes in the management of benign liver tumours: an analysis of 285 patients. HPB (Oxford). 2013;15(2):156-163

21. Bajenaru N, Balaban V, Savulescu F, et al. Hepatic hemangioma-review. $J$ Med Life. 2015;8(spec issue):4-11.

22. Srivastava DN, Gandhi D, Seith A, et al. Transcatheter arterial embolization in the treatment of symptomatic cavernous hemangiomas of the liver: a prospective study. Abdom Imaging. 2001;26(25):510-514.

23. Seo HI, Jo HJ, Sim MS, et al. Right trisegmentectomy with thoracoabdominal approach after transarterial embolization for giant hepatic hemangioma. World J Gastroenterol. 2009;15(27):3437-3439.

24. Lupinacci RM, Szejnfeld D, Farah JF. Spontaneous rupture of a giant hepatic hemangioma. Sequential treatment with preoperative transcatheter arterial embolization and conservative hepatectomy. $G$ Chir. 2011;32(11-12):469-472.

25. Suzuki H, Nimura Y, Kamiya J, et al. Preoperative transcatheter arterial embolization for giant cavernous hemangioma of the liver with consumption coagulopathy. Am J Gastroenterol. 1997;92(4):688-691. 
26. Vassiou K, Rountas H, Liakou P, et al. Embolization of a giant hepatic hemangioma prior to urgent liver resection. Case report and review of the literature. Cardiovasc Intervent Radiol. 2007;30:800-802.

27. Zhou JX, Huang JW, Wu H, et al. Successful liver resection in a giant hemangioma with intestinal obstruction after embolization. World $J$ Gastroenterol. 2013;19(19):2974-2978.

28. Gao J, Ke S, Ding XM, et al. Radiofrequency ablation for large hepatic hemangiomas: initial experience and lessons. Surgery. 2013;153(1):78-85.

29. Alper A, Ariogul O, Emre A, et al. Treatment of liver hemangiomas by enucleation. Arch Surg. 1988;123(5):660-661.

30. Hall GW (2001) Kasabach-Merritt syndrome: pathogenesis and management. Br J Haematol. 2001;112(4):851-862.

31. Ozden I, Emre A, Alper A, et al. Long term result of surgery for liver hemangiomas. Arch Surg. 2000;135(8):978-981.

32. D'Angelica M. What is riskier for the patient with an asymptomatic large hepatic hemangioma: observation or the surgeon? World J Surg. 2013;37(6):1313-1314.

33. Hamaloglu E, Altun H, Ozdemir A, et al. Giant liver hemangioma: therapy by enucleation or liver resection. World J Surg. 2005;29(7):890-893.

34. Lerner SM, Hiatt JR, Salamandra J, et al. Giant cavernous liver hemangiomas: effect of operative approach on outcome. Arch Surg. 2004;139(8):818-821.

35. Patriti A, Graziosi L, Sanna A, et al. Laparoscopic treatment of liver hemangioma. Surg Laparosc Endosc Percutan Tech. 2005;15(6):359-362.

36. Demiryürek H, Alabaz O, Ağdemir $\mathrm{D}$, et al. Symptomatic giant cavernous haemangioma of the liver: is enucleation a safe method? A single institution report. HPB Surg. 1997;10(5):299-304.
37. Fu XH, Lai EC, Yao XP, et al. Enucleation of liver hemangiomas: is there a difference in surgical outcomes for centrally or peripherally located lesions? Am J Surg. 2009;198(2):184-187.

38. Dong J. Precision liver surgery. Chin J Dig Surg. 2014;13:405-411.

39. Liu Y, Wei X, Wang K, et al. Enucleation versus Anatomic Resection for Giant Hepatic Hemangioma: A Meta-Analysis. Gastrointest Tumors. 2016;3(3-4):153-162.

40. Cheng WL, YQ Qi, Wang B, et al. Enucleation versus hepatectomy for giant hepatic haemangiomas: a meta-analysis. Ann $R$ Coll Surg Engl. 2017;99(3):237-241.

41. Gedaly R, Pomposelli JJ, Pomfret EA, et al. Cavernous hemangioma of the liver: anatomic resection vs. enucleation. Arch Surg. 1999;134(4):407-411.

42. Singh RK, Kapoor S, Sahni P, et al. Giant haemangioma of the liver: is enucleation better than resection? Ann $R$ Coll Surg Engl. 2007;89(5):490-493.

43. Qiu J, Chen S, Wu H. Quality of life can be improved by surgical management of giant hepatic haemangioma with enucleation as the preferred option. HPB (Oxford). 2015;17(6):490-494.

44. Acharya M, Panagiotopoulos N, Bhaskaran P, et al. Laparoscopic resection of a giant exophytic liver haemangioma with the laparoscopic Habib 4× radiofrequency device. World J Gastrointest Surg. 2012;4(8):199-202.

45. Gadiyaram S, Shetty N. Laparoscopic resection of giant liver hemangioma using laparoscopic Habib probe for parenchymal transection. J Minim Access Surg. 2012;8(2):59-61.

46. Lanthaler M, Freund M, Nehoda $H$. Laparoscopic resection of a giant liver hemangioma. J Laparoendosc Adv Surg Tech A. 2005;15(6):624-626. 